\title{
Efeito de promotores de crescimento para suínos sobre o desempenho zootécnico, a qualidade intestinal e a eficiência da biodigestão dos dejetos
}

\section{Effect of growth promoters for pigs on live performance, quality intestinal and the efficiency of biodigestion of wastes}

\author{
David Fernandes Gavioli ${ }^{1}$; Eduardo Raele de Oliveira ${ }^{1}$; Aline Alves da Silva ${ }^{1}$; \\ Natália Ceron Romero²; Arturo Pardo Lozano ${ }^{3}$; Roberta Abrami Monteiro Silva ${ }^{3}$; \\ Ana Maria Bridi'; Alexandre $\mathrm{Oba}^{4}$; Caio Abércio da Silva ${ }^{4 *}$
}

\begin{abstract}
Resumo
Objetivou-se avaliar em suínos em fase de crescimento e terminação os efeitos de promotores de crescimento sobre o desempenho, características de carcaça, perfil histológico intestinal, peso dos órgãos do trato digestório, e os reflexos desses tratamentos sobre os efluentes submetidos ao processo de biodigestão. Utilizaram-se 80 suínos, com peso médio inicial de 40,00 $\pm 1,90 \mathrm{~kg}$, submetidos a quatro tratamentos, durante 61 dias, até atingirem 100,00 $\pm 4,50 \mathrm{~kg}$, correspondendo às dietas: Controle, Simbiótico; Colistina (10ppm); e Tilosina (40ppm). Constatou-se diferença na fase de crescimento, com maior consumo diário de ração para o tratamento Tilosina em relação ao tratamento Colistina. Não houve diferença para as características de carcaça, para o peso dos órgãos e para os parâmetros avaliados no processo de biodigestão dos dejetos $(\mathrm{pH}$, sólidos totais, demanda química de oxigênio e demanda bioquímica de oxigênio). Quanto à morfometria intestinal, os animais do tratamento Tilosina apresentaram maior profundidade de cripta $(\mathrm{P} \leq 0,05)$ no duodeno em relação aos animais dos tratamentos Controle e Simbiótico, assim como maior profundidade de cripta no jejuno ( $\mathrm{P} \leq 0,05)$. Houve diferença para a taxa vilosidade/cripta, com o tratamento Controle apresentando maior valor em relação aos demais tratamentos. Para o íleo, houve diferença para a profundidade de cripta dos animais do tratamento Controle em relação ao tratamento Tilosina. Apesar das diferenças observadas para as características de morfometria intestinal, não houve vantagem na utilização dos aditivos para os parâmetros de interesse zootécnico. Quanto aos efeitos sobre a fermentação dos efluentes provenientes dos animais submetidos aos tratamentos, os resultados não indicaram vantagens para nenhum aditivo.

Palavras-chave: Antimicrobiano, dejetos, desempenho, simbiótico
\end{abstract}

\footnotetext{
Abstract

This study aimed to evaluate the effects of growth promoters in growing and finishing pigs on performance and carcass characteristics, intestinal histological profile, organs weight of the digestive tract, and the consequences of these treatments on the effluent through the process of biodigestion. Were used 80 pigs

${ }^{1}$ Discentes do Curso de Mestrado em Ciência Animal, Universidade Estadual de Londrina, UEL, Londrina, PR. E-mail: davidgavioli@hotmail.com; duraele@yahoo.com.br; aline@zootecnista.com.br

2 Discente do Curso de Graduação em Medicina Veterinária, Universidade de Tolima, Colômbia. E-mail: nataliaceron15@hotmail.com

${ }^{3}$ Discentes do Curso de Doutorado em Ciência Animal, UEL, Londrina, PR.E-mail: setaarturo@hotmail.com; roberta_a_silva@ cdargill.com

${ }^{4}$ Profs. Drs. do Dept ${ }^{\circ}$ de Zootecnia, UEL, Londrina, PR. E-mail: ambridi@uel.br; oba@uel.br; casilva@uel.br

* Autor para correspondência
} 
with an average initial weight of $40.00 \pm 1.90 \mathrm{~kg}$, submitted to four treatments, during 61 days, until to reach $100.00 \pm 4.50 \mathrm{~kg}$ of livewight, corresponding to diets with the following additives: Control (diet without growth promoters); Symbiotic; Colistin (10ppm) and Tylosin (40ppm). Difference was observed to the daily feed intake during the growing phase with a greater consumption for the treatment Tylosin regarding treatment Colistin. There were no difference for carcass traits, for the weight of the organs and to the parameters evaluated in the process of digestion of manure $(\mathrm{pH}$, total solids, chemical oxygen demand and biochemical oxygen demand). Regarding the intestinal morphology, animals treated with Tylosin had higher crypt depth $(\mathrm{P} \leq 0.05)$ in the duodenum compared to animals fed with Control and Symbiotic diets, as well as larger crypt depth in the jejunum $(\mathrm{P} \leq 0.05)$. There were differences in the rate villi / crypt with the Control treatment showing higher value compared to other treatments. For the ileum, there was a difference to crypt depth treatment of the animals compared to Control and Tylosin treatments. Despite observed differences in the characteristics of intestinal morphology, there was no advantage in the use of additives for the parameters of zootechnical interest. The effects on the fermentation process did not indicate any advantages for the additives evaluated.

Key words: Antimicrobial, performance, symbiotic, waste

\section{Introdução}

Os antimicrobianos promotores de crescimento têm sido regularmente utilizados nas rações de suínos desde a década de 50, agindo na modulação da microbiota intestinal, diminuindo a incidência de diarréia e melhorando substancialmente o ganho de peso e a eficiência alimentar (PATTERSON, 2005; PARTANEN, 2002). Ao mesmo tempo esta classe de aditivos pode reduzir a espessura do epitélio intestinal em até seis vezes, favorecendo a absorção de nutrientes e implicando numa menor necessidade destes e de energia para manutenção desses tecidos (BELLAVER, 2000).

Todavia, apoiado nos possíveis riscos do desenvolvimento de resistência antimicrobiana devido ao uso prolongado e sob baixas doses, os antibióticos promotores de crescimento (CARVALHO; CARVALHO, 2002), seguindo uma tendência mundial, têm recebido restrições de uso em todo o mundo (MAIORKA; ROCHA; VALLE, 2009). Neste cenário, o uso de promotores alternativos passou a ganhar presença, sendo que os simbióticos, uma combinação de microrganismos probióticos com substâncias prebióticas, têm sido uma classe importante de aditivo utilizada para suínos destinados ao abate (MENTEN, 2001; SANCHES et al., 2005).

Paralelo aos reconhecidos benefícios dos aditivos sobre as características de interesse zootécnico e de saúde intestinal, pouca atenção vem sendo dispensada aos possíveis efeitos da presença de antibióticos nos dejetos biodigestores. Sua ação bactericida pode promover a diminuição da quantidade de bactérias, reduzindo ou até mesmo paralisando a produção do biogás (GASPAR, 2003). Como no Brasil a legislação permite a utilização de alguns antibióticos como promotores de crescimento, entre eles a Colistina e a Tilosina, é importante conhecer a participação destes nos dejetos de suínos destinados ao processo de biodigestão. Ao mesmo tempo, o uso de simbióticos, poderia ser benéfico à fermentação da biomassa do biodigestor.

Assim, este trabalho foi realizado com o objetivo de avaliar os efeitos da utilização de três promotores de crescimento, Colistina, Tilosina e um simbiótico, para suínos em fases de crescimento e terminação, sobre os índices de desempenho, carcaça, histologia intestinal, peso de órgãos digestórios, além de efeitos no processo de biodigestão dos dejetos.

\section{Material e Métodos}

O experimento foi conduzido no Setor de Suinocultura da Fazenda Escola da Universidade Estadual de Londrina, PR. Foram utilizados 40 suínos machos castrados e 40 fêmeas da genética Penarlan, com peso médio inicial de 40,00 $\pm 1,9 \mathrm{~kg}$, 
alojados em baias de alvenaria com piso compacto, $3 \mathrm{~m}^{2}$ e dois animais por baia (um macho castrado e uma fêmea), totalizando 40 baias. Durante o período experimental (61 dias) os animais receberam água e ração à vontade.

O delineamento experimental foi em blocos casualizados (de acordo com o peso inicial dos animais), com quatro tratamentos e 10 repetições por tratamento, sendo cada baia considerada uma unidade experimental.

Os animais foram submetidos aos seguintes tratamentos; 1: Dieta controle isenta de promotores de crescimento; 2: Dieta Controle + Simbiótico (constituído pelos microrganismos: Bacillus subtilis $10^{8} \mathrm{UFC} / \mathrm{g}$, Bifidobacterium longum $10^{8} \mathrm{UFC} / \mathrm{g}$, Enterococcus faecium $10^{8} \mathrm{UFC} / g$, Lactobacillus acidophilus $10^{8} \mathrm{UFC} / \mathrm{g}$, Lactobacillus casei $10^{8}$ UFC/g, Inulina + FOS (Frutooligossacarideos), MOS (Mananooligossacarídeos) e Oligossacarídeos de Soja (Rafinose e Estaquiose) (2 kg/ tonelada); 3 : Dieta Controle + Colistina (10 ppm/tonelada) e 4: Dieta Controle + Tilosina (40 ppm/tonelada).

A inclusão dos antimicrobianos nos tratamentos T3 e T4 seguiram as dosagens recomendadas para promotores de crescimento em suas respectivas fases de tratamento (BRASIL, 1999).

As rações foram formuladas visando atender às exigências nutricionais mínimas para as fases, de suínos fêmeas de alto potencial genético com desempenho superior, de acordo com Rostagno et al. (2005), sendo todas isoenergéticas e isoproteicas. As fases estudadas foram: crescimento I (de 40,0 \pm $1,98 \mathrm{~kg}$ a $54,47 \pm 3,70 \mathrm{~kg}$ ), crescimento II (de 54,47 $\pm 3,70 \mathrm{~kg}$ a $72,44 \pm 4,82 \mathrm{~kg}$ ), terminação I (de 72,44 $\pm 4,82 \mathrm{~kg}$ a $84,28 \pm 4,02 \mathrm{~kg}$ ) e terminação II (de $84,28 \pm 4,02 \mathrm{~kg}$ a $100,42 \pm 4,50 \mathrm{~kg}$ ). Os ingredientes, a composição percentual e os valores calculados das dietas experimentais encontram-se na Tabela 1.

Para avaliação do desempenho foi realizada a pesagem dos animais e o cálculo do arraçoamento destes por fase experimental. Os resultados foram expressos em média de peso final (MPF), ganho de peso diário (GPD), consumo diário de ração (CDR) e conversão alimentar (CA).

Os animais também foram avaliados, a partir de observação diária, para frequência de diarréia, tosse e espirros (MORES et al., 1994; MORES et al., 1995).

Os animais foram submetidos ao manejo préabate descrito em Faucitano (2001) e abatidos com peso médio de $100 \pm 4,5 \mathrm{~kg}$, conforme o RIISPOA (BRASIL, 1952), em um frigorífico comercial localizado no município de Rolândia, e em seguida foram submetidos à pesagem e às avaliações dos órgãos do sistema digestório.

Procedeu-se a retirada e pesagem dos seguintes órgãos: estômago, intestino delgado, intestino grosso e baço. Todo o trato gastrintestinal foi imediatamente esvaziado antes da pesagem. Foram coletadas amostras de duodeno, jejuno e íleo para a elaboração de cortes histológicos, visando avaliar a altura das vilosidades e a profundidade das criptas nestas porções. Para o peso dos órgãos e morfometria intestinal o animal foi considerado como unidade experimental.

Foram amostradas unidades de aproximadamente 2,5 cm de comprimento, retiradas da porção média dos segmentos duodeno, jejuno e íleo de cada animal. As amostras foram abertas pela borda mesentérica, lavadas em água destilada, estendidas pela túnica serosa e fixadas em solução de formol $10 \%$ por $24 \mathrm{~h}$ e, posteriormente, conservadas em álcool $70 \%$ para posterior avaliação da morfometria intestinal. As amostras foram processadas e, então, fixadas em parafina e cortadas em micrótomo American Optical, sendo os cortes feitos com cinco micrômetros de espessura. Em seguida, as lâminas histológicas foram coradas em hematoxilina/eosina. A avaliação morfométrica foi realizada utilizando microscópio óptico Zeizz Axioskop, no aumento de 10 vezes. As imagens foram capturadas com uma Câmera MoticCam 2300 e no programa Motic Image Plus 2.0 foram medidas a altura e espessura das vilosidades e a profundidade das criptas. As 
medidas foram realizadas em 30 vilosidades e criptas, verticais e bem definidas, de cada região intestinal de todos os animais (JUNQUEIRA et al., 2009). A relação das medidas vilosidade: cripta foi calculada dividindo a altura da vilosidade pela profundidade da cripta (HUMASON, 1972).

Tabela 1. Composição percentual, valores nutricionais e energético das rações experimentais.

\begin{tabular}{|c|c|c|c|c|}
\hline \multirow{2}{*}{ Ingredientes (\%) } & \multicolumn{4}{|l|}{ Dietas } \\
\hline & CRESC.I & CRESC. II & TERM. I & TERM. II \\
\hline Farelo de Milho $8 \%$ & 68,91 & 72,37 & 77,70 & 83,51 \\
\hline Farelo de soja $46 \%$ & 27,61 & 24,82 & 20,32 & 14,81 \\
\hline Óleo de soja & 0,70 & 0,40 & - & - \\
\hline Sal Fino & 0,40 & 0,38 & 0,37 & 0,34 \\
\hline Calcário Calcítico & 0,71 & 0,68 & 0,68 & 0,57 \\
\hline Fosfato bicálcico & 0,70 & 0,41 & 0,28 & 0,30 \\
\hline DL-Metionina & 0,12 & 0,10 & 0,04 & 0,01 \\
\hline L-Lisina Pó & 0,33 & 0,33 & 0,24 & 0,15 \\
\hline L-Treonina & 0,12 & 0,11 & 0,07 & 0,01 \\
\hline Suínos Crescimento $^{1}$ & 0,40 & 0,40 & - & - \\
\hline Suínos Terminação & - & - & 0,30 & 0,30 \\
\hline Total & $100 \%$ & $100 \%$ & $100 \%$ & $100 \%$ \\
\hline Proteína Bruta (\%) & 19,02 & 18,00 & 16,20 & 13,99 \\
\hline Extrato Etéreo (\%) & 3,52 & 3,30 & 3,02 & 3,15 \\
\hline Fibra Bruta (\%) & 2,52 & 2,45 & 2,32 & 2,16 \\
\hline Matéria Mineral (\%) & 4,32 & 3,90 & 3,53 & 3,16 \\
\hline Cálcio (\%) & 0,63 & 0,55 & 0,50 & 0,45 \\
\hline Fósforo Total (\%) & 0,45 & 0,39 & 0,35 & 0,34 \\
\hline Fósforo Disponível (\%) & 0,34 & 0,28 & 0,25 & 0,25 \\
\hline En. Metab. Suínos (kcal/kg) & 3299 & 3300 & 3293 & 3304 \\
\hline Lisina Total $(\%)$ & 1,23 & 1,16 & 0,97 & 0,75 \\
\hline Metionina Total (\%) & 0,40 & 0,37 & 0,30 & 0,24 \\
\hline Met + Cist Total (\%) & 0,73 & 0,68 & 0,59 & 0,50 \\
\hline Treonina Total (\%) & 0,82 & 0,77 & 0,67 & 0,52 \\
\hline Isoleucina Total (\%) & 0,75 & 0,70 & 0,62 & 0,52 \\
\hline Valina Total $(\%)$ & 0,86 & 0,81 & 0,73 & 0,63 \\
\hline Triptofano Total (\%) & 0,22 & 0,20 & 0,18 & 0,14 \\
\hline Sódio $(\%)$ & 0,18 & 0,17 & 0,17 & 0,15 \\
\hline Lis Dig Suínos (\%) & 1,10 & 1,04 & 0,86 & 0,66 \\
\hline Met Dig Suínos (\%) & 0,37 & 0,34 & 0,27 & 0,21 \\
\hline M+C Dig Suínos (\%) & 0,66 & 0,62 & 0,53 & 0,45 \\
\hline TRE Dig Suínos (\%) & 0,72 & 0,67 & 0,58 & 0,44 \\
\hline Isol Dig Suínos (\%) & 0,67 & 0,63 & 0,55 & 0,47 \\
\hline Val Dig Suínos (\%) & 0,75 & 0,71 & 0,64 & 0,55 \\
\hline Tri Dig Suínos (\%) & 0,19 & 0,18 & 0,15 & 0,13 \\
\hline Arg Dig Suínos (\%) & 1,13 & 1,05 & 0,93 & 0,77 \\
\hline
\end{tabular}

${ }^{1}$ Composição do premix para suínos em terminação por kg de produto: Ácido fólico (min) 200.1mg, ácido nicotínico (min) 8000 mg, Ácido pantotenico (min) 4000mg, Biotina (min) 30mg, Cobre (min) 27,77g, Colina (min) 27,77g, Enzima 16,67 u/g, Etoxiquin 26,67g, Ferro (min) 300g, Iodo (min) 300mg, Manganês (min) 18g, Selenio (min) 90mg, Vitamina A (min) 20000000UI, Vitamina B1 (min) 400mg, Vitamina B12 (min) 5000mg, Vitamina B2 (min) 1000mg, Vitamina B6 (min) 600mg, Vitamina D3(min) 400000 UI, Vitamina E(min) 10000UI, Vitamina K3 (min), 500mg, Zinco(min) 42g. ${ }^{2}$ Composição do premix para suíno em crescimento: Ácido fólico (min) 187,6mg, Ácido nicotínico (min) $7500 \mathrm{mg}$, Ácido pantotenico (min) 3750mg, Biotina (min) 28,12mg, Cobre (min) 40,5g, Colina (min) 29,94g, Enzima 12,5 u/g, Etoxiquin 20g, Ferro (min) 25g, Iodo (min) 250mg, Manganês (min) $15 \mathrm{~g}$, Selenio (min) 75mg, Vitamina A (min) 1875000UI, Vitamina B1 (min) 375mg, Vitamina B12 (min) 4687,5mg, Vitamina B2 (min) 937,5mg, Vitamina B6 (min) 562,5mg, Vitamina D3(min) 37500 UI, Vitamina E(min) 9375UI, Vitamina K3 (min) 468,7mg, Zinco(min) $35 \mathrm{~g}$.

Fonte: Vitagri®. 
Após o abate foi mensurado o peso de carcaça quente (PCQ) para estimar o rendimento de carcaça em relação ao peso vivo e o peso de abate, de acordo com a fórmula indicada pela ABCS (1973) para cálculos dos rendimentos. Após 24h sob refrigeração a $2 \pm 1^{\circ} \mathrm{C}$, foi obtido o peso das carcaças resfriadas.

As carcaças foram divididas ao meio longitudinalmente e conforme as metodologias descritas pela ABCS (1973) e Bridi e Silva (2009) foram estimadas as seguintes variáveis: comprimento de carcaça (CC), área de olho de lombo (AOL), profundidade de músculo (PROL), espessura de toucinho (ET) e pH inicial e final.

As medidas de $\mathrm{pH}$ inicial e final da carne foram realizadas em dois músculos de referência, o longissimus dorsi (lombo) e o semimembranosus. $\mathrm{O}$ primeiro foi mensurado com um potenciômetro portátil com eletrodo de inserção da marca Testo 205 na altura da última costela, aos 45 minutos após o abate ( $\mathrm{pH}$ inicial) e após $24 \mathrm{~h}$ de resfriamento (pH final) a aproximadamente $2 \pm 1{ }^{\circ} \mathrm{C}$. $\mathrm{O}$ segundo foi mensurado com o potenciômetro localizado aproximadamente $2 \mathrm{~cm}$ do centro deste músculo, afastado da superfície.

Para a análise de cor as amostras foram analisadas $24 \mathrm{~h}$ após o abate, utilizando o colorímetro portátil Minolta ${ }^{\circledR}$ CR10, com esfera de integração e ângulo de visão de $8^{\circ}$. Os componentes L* (luminosidade), a* (componente vermelho-verde) e $b^{*}$ (componente amarelo-azul) foram expressos no sistema de cor CIELAB. Com esses valores, calculou-se o ângulo de tonalidade $\left(h^{*}\right)$ pela equação $h^{*}=\tan -1\left(b^{*} / a^{*}\right)$, e o índice de saturação $\left(\mathrm{c}^{*}\right)$ a partir da equação $\mathrm{c}^{*}=\left(\mathrm{a}^{*} 2+\right.$ b*2)0,5 (MINOLTA, 1998).

Para identificação de possíveis efeitos dos tratamentos com promotores de crescimento sobre a eficiência do biodigestor foram elaborados 20 biodigestores experimentais (um para cada uma das 20 baias selecionadas ao acaso), modelo batelada, que consiste no abastecimento único do biodigestor e de um período de retenção hidráulico adequado para a biodigestão dos resíduos (DEGANUTTI et al., 2004).

O delineamento experimental para a análise dos biodigestores foi completamente casualizado, com quatro tratamentos e cinco repetições por tratamento. Foram utilizados fezes procedentes de 20 baias, ocupadas por um suíno macho castrado e uma fêmea com peso médio de 86,4 $\pm 4,3 \mathrm{~kg}$. As baias foram definidas como unidade experimental.

Esses biodigestores foram constituídos de um balão volumétrico de vidro cor âmbar de 5 litros hermeticamente fechado com uma tampa de vedação (rolha de borracha) onde foi acoplada uma mangueira plástica (equipo para soro macro gotas) para que pudesse permitir a saída do gás produzido durante o processo fermentativo, sendo que a outra extremidade da mangueira estava imersa em um béquer de $500 \mathrm{~mL}$ contendo água para impedir a entrada de ar no biodigestor. O modelo dos biodigestores experimentais foram adaptados de Souza, Lucas Júnior e Ferreira (2005).

$\mathrm{Na}$ fase de terminação foi realizada uma única coleta de $1 \mathrm{~kg}$ de fezes de cada uma das 20 baias, sendo estas posteriormente diluídas em água numa proporção de 1:6 para formarem os afluentes que foram analisados quanto aos parâmetros $\mathrm{pH}$, sólidos totais, demanda química de oxigênio (DQO) e demanda bioquímica de oxigênio (DBO), de acordo com APHA (2005) e então, colocados nos biodigestores.

Em seguida os biodigestores foram alojados em um ambiente fechado, sobre um piso suspenso ripado, sob a incidência constante de uma lâmpada incandescente. Permaneceram assim no local, por um período de 60 dias, sob uma temperatura máxima média de $38 \pm 1,5^{\circ} \mathrm{C}$, que foi aferida duas vezes ao dia com a utilização de termômetros de temperaturas máximas e mínimas $\left(-40^{\circ} \mathrm{C}+50^{\circ} \mathrm{C}\right)$. Após esse período o efluente foi devidamente homogeneizado e amostras foram novamente 
coletadas e encaminhadas ao mesmo laboratório para que fossem avaliadas sobre os mesmos parâmetros iniciais.

Com as análises iniciais e finais das variáveis de fermentação dos biodigestores, foi feito a diferença entre os valores, mensurando-se a redução dos valores encontrados, demonstrando a qualidade dos efluentes.

Os dados foram submetidos à análise de variância ANOVA, utilizando-se o pacote estatístico MINITAB 1.6 (2010). Para testar a diferença entre as médias, foi utilizado o teste de Tukey com nível de significância de 5\%.

\section{Resultados e Discussão}

Para os parâmetros avaliados de desempenho verificou-se apenas diferença $(\mathrm{P} \leq 0,05)$ para $\mathrm{o}$ consumo diário de ração entre os tratamentos Tilosina e Colistina na fase de crescimento I (Tabela 2). O grupo tratado com Tilosina apresentou maior consumo em relação ao grupo tratado com Colistina. Todavia não houve diferença destes para o grupo do Controle e para o grupo tratado com Simbiótico. A Tilosina é um macrolídeo capaz de alterar a microbiota intestinal, seu uso em leitões está relacionado a uma melhora na performance do animal, sobretudo, relacionado ao consumo de ração e conversão alimentar. Um dos mecanismos que podem explicar essa melhora no desempenho corresponde a um aumento na massa relativa de lactobacilos no intestino quando relacionada com as bactérias enterogênicas devido a uma diminuição marcante e permanente destas com o uso deste antibiótico por pelo menos duas semanas (BOSI et al., 2011). Collier et al. (2003) demonstraram um maior percentual de lactobacilos na flora intestinal de animais que recebem Tilosina como promotor de crescimento, quando comparados com tratamentos que continham a inclusão de outros aditivos antimicrobianos, atribuindo as melhores taxas de desempenho dos animais a este efeito. A Colistina é uma polimixina com ação seletiva específica frente a bactérias gramnegativas, principalmente, a Escherichia coli (SILVA; ZOTTI, 2010). Além disso, a Colistina pode reduzir as bactérias gram-negativas e benéficas da flora intestinal e não tem ação sobre gram-positivas (SPINOSA, 2006), podendo esta ação seletiva, quando comparada à ação da Tilosina para a fase estudada neste trabalho, ser a causa de desempenho inferior desta polimixina em relação ao macrolídeo estudado. Outra causa pode estar relacionada à adaptação inicial das dietas utilizadas na primeira fase experimental (crescimento 1), pois as características sensoriais destes antibióticos são diferentes, sobretudo a Colistina, que incorpora um sabor amargo ao alimento, podendo levar a uma redução inicial de consumo da dieta com a presença do antibiótico.

Ao compararem o uso de antimicrobianos com promotores de crescimento alternativos e com dietas livres destes, Houdijk et al. (1998) e Budiño (2004) observaram resultados de desempenho contraditórios nas fases de crescimento e terminação. Nos demais períodos experimentais não houve diferença $(\mathrm{P}>0,05)$ para nenhuma variável de desempenho analisada. Este resultado se deve provavelmente ao bom manejo alimentar e sanitário mantido durante todo o período experimental, comprovados pela ausência de tosse e quadros severos de diarreia, não permitindo que os tratamentos apresentassem resultados mais expressivos sobre os parâmetros de desempenho (BORATTO et al., 2004).

Santos (2002), Cardoso, Mestre e Pickard (2004), Rekiel, Wiecek e Dziuba (2005) e Campbell et al. (2006), trabalhando com diferentes aditivos promotores de crescimento, incluindo prebióticos e antibióticos, também não encontraram diferenças para o desempenho nas fases de crescimento e terminação.

Para as características de carcaça (Tabelas 3 e 4) não foram encontradas diferenças $(\mathrm{P}>0,05)$ entre os 
tratamentos para nenhuma das variáveis avaliadas. Os resultados são semelhantes aos observados por Chiquieri, Sousa e Ventura (2006), que também não observaram diferenças entre o uso de antibióticos, probióticos e/ou prebióticos sobre as características de carcaça de suínos. Do mesmo modo, os dados também se identificaram com os obtidos por Rekiel, Wiecek e Dziuba (2005), que não notaram efeitos nos parâmetros de carcaça de suínos quando estudaram a adição de mananoligossacarídeos e antibióticos na dieta, e por Junqueira et al. (2009), que não encontraram diferenças sobre as características de carcaça (peso da carcaça, rendimento de carne, espessura de toucinho, espessura do músculo e percentagem de carne magra) nos suínos tratados com antibiótico e simbiótico. Para os antibióticos, o efeito do aumento de produtividade da carcaça esperado está relacionado com a melhora do ganho de peso; diminuição do tempo necessário para que se atinja o peso ideal para o abate (tempo de engorda); e diminuição da quantidade de alimento consumido pelo animal até o momento do abate (aumento da eficiência alimentar) (PALERMO-NETO, 2006), levando a uma diminuição do teor em gordura das carcaças e um incremento no percentual de carne magra do animal.
Estes valores indicam que os promotores de crescimento analisados não promoveram efeitos positivos para essas variáveis, quando comparados com o grupo Controle, entretanto, estes resultados não excluem a eficácia dos produtos. Esses valores podem novamente ser atribuídos às boas condições experimentais, como a qualidade da ração, a desinfecção de instalações e de equipamentos e o manejo adequado, como também foi relatado por Santos et al. (2005). Segundo Corassa (2004), sob condições ambientais, de manejo e sanitárias inferiores ou mais desafiadoras, a eficácia dos promotores de crescimento pode ser mais evidenciada. Pode-se atribuir que o bom estado sanitário e de saúde dos animais, permitiu que estes pudessem desenvolver seu potencial de crescimento. Como os aditivos promotores de crescimento agem, entre outras formas, promovendo uma melhora do status sanitário (RUTZ; FERKET; SANTOS, 2007) e uma manutenção do equilíbrio inflamatório do intestino (NIEWOLD, 2007), a ausência de fatores negativos ao desempenho dos animais faz com que a resposta destes aos promotores seja similar ao de animais que não receberam esses aditivos na dieta, não permitindo o aparecimento das características benéficas destes produtos sobre os parâmetros zootécnicos. 


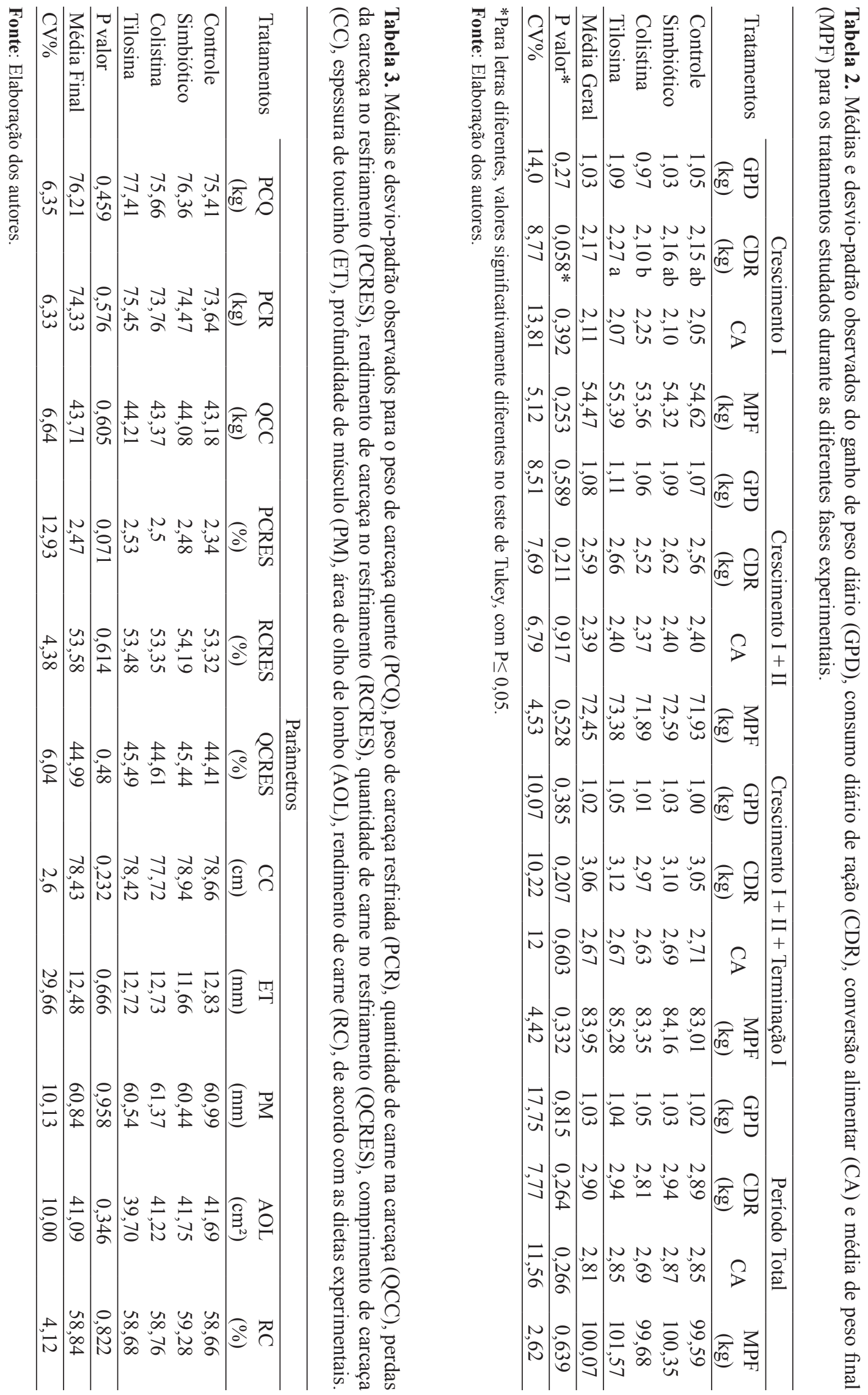


Tabela 4. Médias de $\mathrm{pH}$ inicial, final e cor da carne de acordo com os tratamentos estudados.

\begin{tabular}{lccccc}
\hline \multirow{2}{*}{ Tratamentos } & \multicolumn{5}{c}{ Parâmetros } \\
\cline { 2 - 5 } & $\mathrm{pH}$ inicial & $\mathrm{pH}$ final & cor L & $\mathrm{a}^{*}$ & $\mathrm{~b}^{*}$ \\
\hline Controle & 6,01 & 5,62 & 53,68 & 5,99 & 10,57 \\
Simbiótico & 6,05 & 5,63 & 53,93 & 5,24 & 10,22 \\
Colistina & 6,00 & 5,64 & 54,47 & 6,07 & 10,58 \\
Tilosina & 6,17 & 5,67 & 54,48 & 5,46 & 10,48 \\
\hline P valor & 0,34 & 0,224 & 0,942 & 0,119 & 0,573 \\
\hline Média Geral & 6,06 & 5,64 & 54,14 & 5,69 & 10,46 \\
\hline CV\% & 5,47 & 1,4 & 4,17 & 27,06 & 10,2 \\
\hline
\end{tabular}

Fonte: Elaboração dos autores.

Para o peso final do estômago, intestino foram observadas diferenças $(\mathrm{P}>0,05)$ entre os delgado, intestino grosso e baço (Tabela 5), não tratamentos.

Tabela 5. Médias do peso absoluto $(\mathrm{kg})$ e de peso relativo (\%) do estômago, intestino delgado, intestino grosso e baço de suínos abatidos com peso médio de 100,42 $\pm 4,50 \mathrm{~kg}$.

\begin{tabular}{lcccccccc}
\hline \multirow{2}{*}{ Tratamentos } & \multicolumn{2}{c}{ Estômago } & \multicolumn{2}{c}{ Intestino Delgado } & \multicolumn{2}{c}{ Intestino Grosso } & \multicolumn{2}{c}{ Baço } \\
\cline { 2 - 7 } & $(\mathrm{kg})$ & $(\%)$ & $(\mathrm{kg})$ & $(\%)$ & $(\mathrm{kg})$ & $(\%)$ & $(\mathrm{kg})$ & $(\%)$ \\
\hline Controle & 0,57 & 0,58 & 1,63 & 1,63 & 1,74 & 1,74 & 0,16 & 0,16 \\
Simbiótico & 0,55 & 0,55 & 1,59 & 1,58 & 1,72 & 1,71 & 0,14 & 0,14 \\
Colistina & 0,55 & 0,56 & 1,55 & 1,55 & 1,68 & 1,69 & 0,15 & 0,15 \\
Tilosina & 0,56 & 0,56 & 1,55 & 1,54 & 1,71 & 1,70 & 0,15 & 0,15 \\
\hline P valor & 0,621 & & 0,677 & & 0,943 & & 0,374 & \\
\hline Média Geral & 0,56 & 0,56 & 1,58 & 1,58 & 1,71 & 1,71 & 0,15 & 0,15 \\
\hline CV\% & 11,03 & 17,01 & 17,26 & 10,03 & 15,69 & 14,92 & 17,31 & 17,06 \\
\hline
\end{tabular}

Fonte: Elaboração dos autores.

Um dos efeitos mais importantes dos prebióticos/ probióticos é sua capacidade de modular as respostas imunológicas (DAWSON; PIRVULESCU, 1999), contudo, para o peso absoluto e relativo do baço e do intestino delgado e intestino grosso, órgãos que exercem atividade imunológica, não foram observadas influências $(\mathrm{P}>0,05)$ dos tratamentos.

Estes resultados também contrariam as hipóteses de possíveis diferenças entre tratamentos, dada à característica que os antimicrobianos têm de atuar na redução da quantidade de microrganismos produtores de toxinas aderidos ao epitélio intestinal, levando à diminuição da espessura da parede intestinal (ANDERSON et al., 1999).
Também para animais tratados com antibióticos promotores de crescimento, os microrganismos presentes no intestino podem ser menos efetivos na fermentação microbiana e na consequente produção de ácidos graxos voláteis, que fornecem boa parte da energia exigida para o desenvolvimento dos enterócitos (LIN; VISEK, 1991), reduzindo a taxa de replicação celular no epitélio intestinal, promovendo assim a redução dos pesos relativos dos intestinos delgado e grosso (COSTA; TSE; MIYADA, 2007).

Para o peso dos órgãos avaliados, sabe-se que as vísceras têm um metabolismo elevado e são responsáveis por uma parcela significativa 
das exigências de manutenção que podem ser exacerbadas com situações de desequilíbrios metabólicos (NOBLET et al., 1994). A ausência de diferenças $(\mathrm{P}>0,05)$ entre os tratamentos para o peso das vísceras, portanto, pode ser justificada pelos animais terem sido mantidos em um bom estado sanitário durante todo o período experimental, proporcionando um baixo desafio imunológico (OETTING et al., 2006). O mesmo pode ter ocorrido dada a oferta de dietas altamente digestíveis durante o experimento, que podem limitar o desenvolvimento de bactérias no trato intestinal pela redução de substrato disponível ao crescimento bacteriano, diminuindo, assim, o potencial antimicrobiano dos promotores de crescimento (COSTA; TSE; MIYADA, 2007).

Os resultados das medidas morfométricas da mucosa das porções do intestino delgado (Tabela 6) apontam diferenças $(\mathrm{P} \leq 0,05)$ entre os tratamentos. Os animais que compunham o grupo tratado com ração contendo Tilosina tiveram maior profundidade de cripta no duodeno em relação aos animais que receberam o simbiótico e os animais controle, sugerindo que os animais tratados com Tilosina obtiveram uma maior descamação epitelial do intestino nesta porção, pois, o aumento na descamação resulta em incremento da profundidade da cripta para assegurar a adequada taxa de renovação celular e garantir a reposição das perdas de células da região apical dos vilos (PLUSKE; HAMPSON; WILLIAMS, 1997; TUCCI, 2003). A altura de vilosidade teve comportamento contrário, com a Tilosina apresentando a pior taxa vilosidade/ cripta entre os tratamentos e a menor altura de vilosidade em relação à Colistina.

Mesmo sabendo que quanto maior a altura das vilosidades e menor a profundidade das criptas melhor será a absorção de nutrientes e menores serão as perdas energéticas com o turnover celular (OETTING et al., 2006), o desempenho zootécnico desses animais não apresentou alterações negativas, quando comparados com os outros tratamentos. Talvez este resultado esteja associado ao fato do duodeno corresponder à primeira porção proximal do intestino delgado, não tendo como função principal a absorção, e sim a digestão química (JUNQUEIRA; CARNEIRO, 2011).

Houve também diferença para profundidade de cripta do jejuno $(\mathrm{P} \leq 0,05)$, onde os animais tratados com Tilosina apresentaram os maiores valores, enquanto que os animais dos tratamentos com Colistina e Simbiótico apresentaram maiores profundidades de cripta em relação ao tratamento Controle. Não houve diferença para altura de vilosidades do jejuno, assim como no trabalho realizado por Chiquieri, Sousa e Ventura (2006), que também ao estudar os efeitos do uso de antimicrobianos, probiótico e prebiótico para suínos, verificaram ausência de diferença para o parâmetro entre os tratamentos. Entretanto, no presente trabalho foi observada diferença para a taxa vilosidade/cripta, com o tratamento controle apresentando a maior taxa.

Para o íleo, houve diferença apenas para a profundidade de cripta para os animais do grupo Controle em relação ao grupo que recebeu Tilosina, sendo os primeiros melhores.

De acordo com Oetting et al. (2006) e Junqueira et al. (2009), para a comparação de aditivos promotores de crescimento, quer para características de desempenho ou carcaça, ou de caráter morfohistologico intestinal, devem ser considerados os níveis utilizados e suas características de ação, além da idade dos animais. 


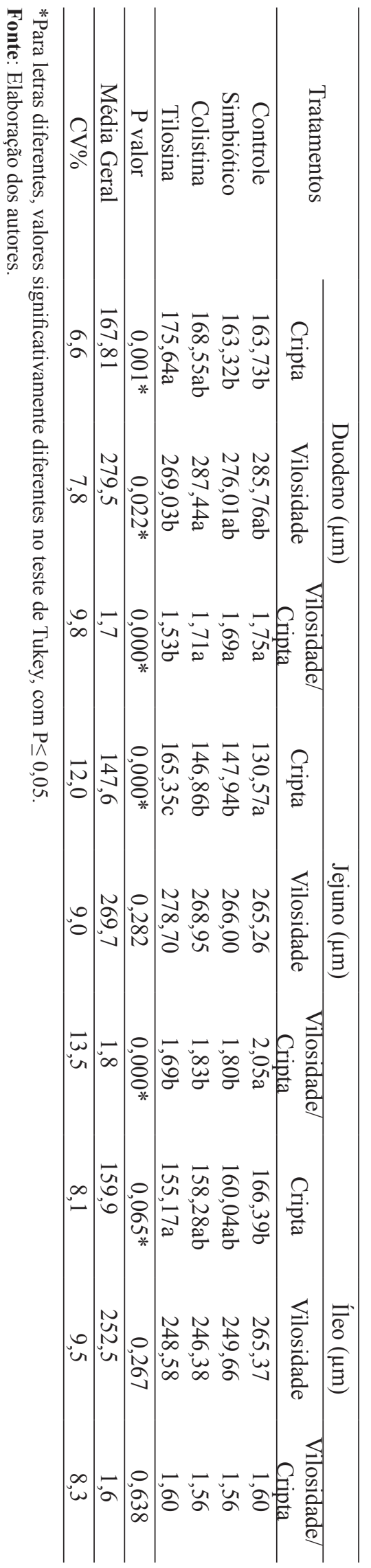

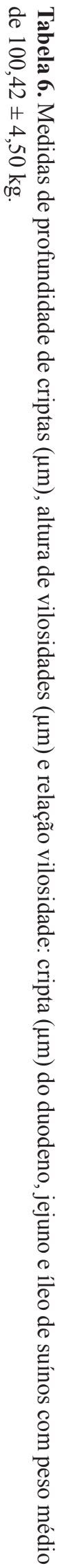


Para a avaliação das fezes submetidas ao processo de biodigestão, observou-se que ocorreu uma redução (expressa em porcentagem na Tabela 7) dos valores de $\mathrm{DBO}, \mathrm{DQO}, \mathrm{pH}$ e $\mathrm{ST}$, indicando o êxito do processo fermentativo. Porém, não foram encontradas diferenças $(\mathrm{P}>0,05)$ da biofermentação entre os tratamentos na redução das variáveis analisadas dos efluentes.

Tabela 7. Médias observados na redução da demanda bioquímica de oxigênio (DBO), demanda química de oxigênio (DQO), pH final (pH) e sólidos totais (ST) após processos de biodigestão.

\begin{tabular}{lcccc}
\hline \multirow{2}{*}{ Tratamentos } & \multicolumn{4}{c}{ Parâmetros } \\
\cline { 2 - 5 } & $\mathrm{DBO} \%$ & $\mathrm{DQO} \%$ & $\mathrm{pH}$ & $\mathrm{ST} \%$ \\
\hline Controle & 33,56 & 41,77 & 6,09 & 52,86 \\
Simbiótico & 21,39 & 25,88 & 5,99 & 48,57 \\
Colistina & 23,01 & 35,53 & 6,18 & 46,43 \\
Tilosina & 39,96 & 38,81 & 6,14 & 47,44 \\
\hline Média Geral & 29,48 & 35,50 & 6,10 & 48,82 \\
\hline P valor & 0,108 & 0,376 & 0,180 & 0,923 \\
\hline CV\% & 47,90 & 41,66 & 2,32 & 30,39 \\
\hline
\end{tabular}

Fonte: Elaboração dos autores.

Reconhecendo que, quando empregado nas dietas de animais como promotores de crescimento, pequenas concentrações de antibióticos são comumente encontradas em amostras de lodo ou de efluentes provenientes de estações de tratamento de esgoto, e conhecendo a ação destes contra as bactérias presentes no trato intestinal, esperava-se que os efluentes oriundos de animais tratados com Tilosina e Colistina resultassem um processo de fermentação menos eficiente em relação aos efluentes provenientes de animais tratados com rações com Simbiótico e Controle. Este hipótese levaria a interferências no produto final da biodigestão, com prejuízos para o meio ambiente e para o sistema de produção (GIGER et al., 2003; WATKINSON; MURBY; COSTANZO, 2007; REGITANO; LEAL, 2010). Todavia, os antibióticos utilizados não prejudicaram a fermentação e tampouco os simbióticos favoreceram o processo fermentativo. Levando-se em conta a condição experimental do estudo, combinado com o escasso número de trabalhos nesta área, são necessários mais estudos para melhor compreensão desses resultados.

\section{Conclusões}

Frente a todos os parâmetros avaliados por este estudo, pode-se concluir que o desempenho não foi afetado pela escolha do aditivo, assim como as características de carcaça e a eficiência da biodigestão das fezes. A avaliação morfométrica do uso destes promotores, em especial da Colistina e da Tilosina, apresentaram diferenças nos diferentes segmentos intestinais, entretanto, estas diferenças não influênciaram os parâmetros zootécnicos e ambientais avaliados.

\section{Referências}

ANDERSON, D. B.; McCRACKEN, V. J.; AMINOV, R. I.; SIMPSON, J. M.; MACKIE, R. I.; VERSTEGEN, M. W. A.; GAS, H. R. Gut microbiology and growthpromoting antibiotics in swine. Pigs News Information, Adelaide, v. 20, n. 4, p. 115-122, 1999.

AMERICAN PUBLIC HEALTH ASSOCIATION APHA. Standard methods for examination of water and wastewater. Washington: American Water Works Association, 2005. p. 1325.

ASSOCIAÇÃO BRASILEIRA DE CRIADORES DE SUÍNOS - ABCS. Métodos brasileiros de classificação de carcaças. 2. ed. Rio Grande do Sul: Estrela, 1973. 17 
p.

BELLAVER, C. O uso de microingredientes (aditivos) na formulação de dietas para suínos e suas implicações na produção e na segurança alimentar. In: CONGRESSO MERCOSUL DE PRODUÇÃO SUÍNA, 1., 2000, Buenos Aires. Anais... Buenos Aires: FCV, UBA; FAV, UNRC; EMBRAPA, 2000. p. 93-108.

BORATTO, A. J.; LOPES, D. C.; OLIVEIRA, R. F. M.; ALBINO, L. F. T.; SÁ, L. M.; OLIVEIRA, G. A. Uso de antibiótico, de probiótico e de homeopatia em frangos de corte criados em ambiente de conforto, inoculados ou não com Escherichia coli. Revista Brasileira de Zootecnia, Viçosa, v. 33, n. 6, p. 1477-1485, dez. 2004.

BOSI, P.; MERIALDI, G.; SCANDURRA, S.; MESSORI, S.; BARDASI, L.; NISI, I.; RUSSO, D.; CASSINI, L.; TREVISI, P. Feed supplemented with 3 different antibiotics improved food intake and decreased the activation of the humoral immune response in healthy weaned pigs but had differing effects on intestinal microbiota. Journal of Animal Science, Champaign, v. 89, n. 12, p. 4043-4053, 2011.

BRASIL. Decreto $n^{\circ}$ 30.691, de 29 de março de 1952. Regulamento industrial e sanitário de produtos de origem animal - RIISPOA. Diário Oficial [da] União, Brasília, 29 mar. 1952, Seção 1, p. 10785.

- Instrução Normativa $n^{\circ} 3$, de 22 de janeiro de 1999. 1999. Disponível em: <http://sistemasweb. agricultura.gov.br/sislegis/action/detalhaAto.do?method =consultarLegistacaoFederal $>$. Acesso em: 15 mar. 2012.

BRIDI, A. M.; SILVA, C. A.; Avaliação da carcaça. In: 2009. p. 1-15. Avaliação da carne suína. Londrina: Midiograf,

BUDIÑO, F. E. L. Probiótico elou prebiótico na dieta de leitões recém desmamados. 2004. Tese. (Doutorado em Zootecnia) - Faculdade de Ciências Agrárias e Veterinárias. Universidade Estadual Paulista, Jaboticabal.

CAMPBELL, A. J.; GARDINER, G. E.; LEONARD, F. C.;LYNCH, P.B.; STANTON, C.; ROSS, R. P.; LAWLOR, P. G. The effect of dietary supplementation of finishing pigs with organic acids or mannanoligosaccharide on the coliform, Lactobacillus and Bifidobacterium flora of intestinal contents and faeces. The Pig Journal, Chicago, v. 57, p. 90-104, may, 2006.

CARDOSO, A. M. S.; MESTRE, R. B.; PICKARD, J. A. Grower-finishers fed Bio-Mos ${ }^{\circledR}$ achieve performance levels comparable to those achieved with an antibiotic growth promoter. In: INTERNATIONAL ANNUAL FEED INDUSTRY SYMPOSIUM, 20., 2004, Lexington. Proceedings... Lexington: Alltech, 2004. p. 52.

CARVAlHO, R. D. S.; CARVAlHO, W. A.
Eritromicina, Azitromicina e claritromicina. In: SILVA, P. Farmacologia. 6. ed. Rio de Janeiro: Guanabara Koogan, 2002. cap. 105, p. 1059-1071.

CHIQUIERI, J. M. S.; SOUSA, J. C. D.; VENTURA, B. G. Probiotico y prebiotico em la alimentation de cerdos em crescimento y terminacyon. Archivo Zootecnico, Córdoba, v. 55, n. 211, p. 305-308, 2006.

COLLIER, C. T.; SMIRICKY-TJARDES, M. R.; ALBIN, D. M.; WUBBEN, J. E. V.; GABERT, M.; DEPLANCKE, B.; BANE, D.; ANDERSON, D. B.; GASKINS, H. R. Molecular ecological analysis of porcine ileal microbiota responses to antimicrobial growth promoters. Journal Animal Science, Champaign, v. 81, n. 12, p. 3035-3045, 2003.

CORASSA, A. Mananoligossacarídeos, ácidos orgânicos e probióticos em dietas para leitões de 21 a 49 dias de idade. 2004. Dissertação (Mestrado em Zootecnia) - Universidade Federal de Viçosa, Viçosa.

COSTA, L. B.; TSE, M. L. P.; MIYADA, V. S. Extratos vegetais como alternativas aos antimicrobianos promotores de crescimento para leitões recémdesmamados. Revista Brasileira de Zootecnia, Viçosa, v. 36, n. 3, p. 589-595, 2007.

DAWSON, K. A.; PIRVULESCU, M. Mananoligossacarídeos derivados de leveduras como moduladores da resposta imunológica e alternativas aos promotores de crescimento antimicrobianos. In: RONDA LATINO AMERICANA DA ALLTECH, 9., 1999, Curitiba. Anais... Curitiba: Alltech, 1999. p. 33-41.

DEGANUTTI, R.; PALHACI, M. C. J. P.; ROSSI, M.; TAVARES, R.; SANTOS, C. Biodigestores rurais: modelo indiano, chinês e batelada. In: CONGRESSO BRASILEIRO DE ENGENHARIA AGRÍCOLA, 33., 2004, Águas de São Pedro. Anais... Campinas: Sociedade Brasileira de Engenharia Agrícola, 2004. 1 CD-ROM.

FAUCITANO, L. Efeitos do manuseio pré-abate sobre o bem-estar e sua influência sobre a qualidade da carne. In: CONFERÊNCIA INTERNACIONAL VIRTUAL SOBRE QUALIDADE DA CARNE SUÍNA, 2., 2001, Concórdia. Anais... Concórdia: Embrapa Suínos e Aves, 2001. v. 2, p. 55-75.

GASPAR, R. M. B. L. Utilização de biodigestores em pequenas e médias propriedades rurais com ênfase na agregação de valor: um estudo de caso na região de Toledo-PR. 2003. Dissertação (Mestrado em Engenharia de Produção) - Universidade Federal de Santa Catarina, Florianópolis.

GIGER, W.; ALDER, A. C.; GOLET, E. M.; KOHLER, H. P. E.; McARDELL, C. S.; MOLNAR, E.; SIEGRIST, H.; SUTER, M. J. F. Occurrence and fate of antibiotics 
as trace contaminants in wastewaters, sewage sludge's, and surface waters. Chimia, Bern, v. 57, n. 9, p. 485-491, 2003.

HOUDIJK, J. G. M.; BOSCH, M. W.; VERSTEGEN, H. J.; BERENTAS, H. J. Effects of dietary oligosaccharides on the growth performance and faecal characteristics of young growing pigs. Animal Feed Science and Technology, Amsterdam, v. 71, n. 1, p. 35-48, 1998.

HUMASON, G. L. Animal tissue techniques. 3. ed. São Francisco: WH Freeman, 1972. 641 p.

JUNQUEIRA, L. C.; CARNEIRO, J. O trato digestivo. In: Histologia básica. 11. ed. Rio de Janeiro: Guanabara Koogan, 2011. p. 283-316.

JUNQUEIRA, O. M.; BARBOSA, L. C. G. S.; PEREIRA, A. A.; ARAÚJO, L. F.; GARCIA NETO, M.; PINTO, M. F. Uso de aditivos em rações para suínos nas fases de creche, crescimento e terminação. Revista. Brasileira de Zootecnia, Viçosa, v. 38, n. 12, p. 2394-2400, dez. 2009.

LIN, H. C.; VISEK, W. J. Colon mucosal cell damage by ammonia in rats. Journal of Nutrition, Philadelphia, v. 121, n. 5, p. 887-893, 1991.

MAIORKA, A.; ROCHA, C. R.; VALLE, F. L. P. Impacto na saúde intestinal das aves pelo uso de produtos alternativos aos promotores de crescimento. Universidade Federal do Paraná. Agromais, Chapecó, Ed. 17, 2009.

MENTEN, J. F. M. Aditivos alternativos na nutrição de aves: probióticos e prebióticos. In: REUNIÃO ANUAL DA SOCIEDADE BRASILEIRA DE ZOOTECNIA, 38., 2001, Piracicaba. Anais... Piracicaba: SBZ, 2001. p. 141-157.

MINOLTA. Precise color communication: color control from perception to instrumentation. Sakai: [s.n], 1998. (Encarte).

MORÉS, N.; BARIONI JÚNIOR, W.; SOBESTIANSKY, J.; COSTA, O. A. D.; PIFFER, I. A.; PAIVA, D. P. ; GUZZO, R.; COIMBRA, J. B.; VIEIRA, R. P.; AMARAL, A. L. Estimativa dos índices de pneumonia, pela tosse, e de rinite atrófica, por espirros, em suínos. Arquivo Brasileiro de Medicina Veterinária e Zootecnia, Belo Horizonte, v. 53, n. 3, p. 284-289, 1994.

MORÉS, N.; SOBESTIANSKY, J.; VIEIRA, R. P.; BARIONI JÚNIOR, W; AMARAL, A. L. Estudo epidemiológico sobre problemas em leitões lactentes em criações no Sul do Brasil. Arquivo Brasileiro de Medicina Veterinária e Zootecnia, Belo Horizonte, v. 47, n. 4, p. 549-559, 1995.

NIEWOLD, T. A. The Nonantibiotic anti-Inflammatory effect of antimicrobial growth promoters, the real mode of action? A hypothesis. Poultry Science, Champaign, v.
86, n. 4, p. 605-609, 2007

NOBLET, J.; FORTUNE, H.; SHI, X. S.; DUBOIS, S. Prediction of net energy value of feeds for growing pigs. Journal of Animal Science, Champaign, v. 72, n. 2, p. 344-354, 1994.

OETTING, L. L.; UTIYAMA, C. E.; GIANI, P. A.; RUIZ, U. S.; MIYADA, V. S. Efeitos de extratos vegetais e antimicrobianos sobre a digestibilidade aparente, o desempenho, a morfometria dos órgãos e a histologia intestinal de leitões recém-desmamados. Revista Brasileira de Zootecnia, Viçosa, MG, v. 35, n. 4, p. 13891397, 2006.

PALERMO-NETO, J. Considerações gerais sobre o uso de agentes que alteram a produção animal. In: SPINOSA, H. S.; GÓRNIAK, S. L.; BERNARDI, M. M. Farmacologia aplicada à medicina veterinária. 4. ed. Rio de Janeiro: Guanabara Koogan, 2006. p. 588-595.

PARTANEN, K. Uso de aditivos na produção de suínos. In: SIMPÓSIO SOBRE MANEJO E NUTRIÇÃO DE AVES E SUÍNOS E TECNOLOGIA NA PRODUÇÃO DE RAÇÕES, 1., 2002, Campinas. Anais... Campinas: Colégio Brasileiro de Nutrição Animal, 2002. p. 45-62.

PATTERSON, J. A. Prebiotic feed additives: rational and use in pigs. Advances in Pork Production, Edmonton, v. 16, n. 13, p. 149-159, 2005.

PLUSKE, J. R.; HAMPSON, D. J.; WILLIAMS, I. H. Factors influencing the structure and function of the small intestine in The weaned pig: a review. Livestock Production Science, Amsterdam, v. 51, n. 1-3, p. 215236, 1997.

REGitANO, J. B.; LEAL, R. M. P. Comportamento e impacto ambiental de antibióticos usados na produção animal brasileira. Revista Brasileira de Ciência do Solo, Viçosa, v. 34, n. 4, p. 601-616, 2010.

REKIEL, A.; WIECEK, J.; DZIUBA, M. Effect of feed additives on the results of fattening and selected slaughter and quality traits of pork meat of pigs with different genotypes. Czech Journal of Animal Science, Prague, v. 50, n. 12, p. 561-567, 2005.

ROSTAGNO, H. S.; ALBINO, L. F. T.; DONZELE, J. L.; GOMES, P. C.; OLIVEIRA, R. F.; LOPES, D. C.; FERREIRA, A. S.; BARRETO, S. L. T. Tabelas brasileiras para aves e suínos: composição de alimentos e exigências nutricionais. Viçosa: Ed. UFV, 2005. 153 p.

RUTZ, F.; FERKET, P. R.; SANTOS, A. A. Antibióticos como promotores e impacto na saúde animal. In: BRIDI, A. M.; FONSECA, N. A. N.; SILVA, C. A.; PINHEIRO, J. W. A zootecnia frente a novos desafios. Londrina: UEL, 2007. p. 369-406. 
SANCHES, A. L.; LIMA, J. A. F.; FIALHO, E. T.; MURGAS, L. D. S.; ALMEIDA, E. D.; VIEIRA NETO, J.; FREITAS, R. T. F. Utilização de probiótico, prebiótico e simbiótico em rações de leitões ao desmame. Ciências Agrotécnica, Lavras, v. 30, n. 4, p. 774-777, 2005.

SANTOS, E. C.; TEIXEIRA, A. S.; FREITAS, R. T. F.; DIAS, E. S.; RODRIGUES, P. B.; MURGAS, L. D. S.; OLIVEIRA, R. F. M.; SANTOS, E. C.; GACHETT, N. A .B. Uso de aditivos promotores de crescimento sobre o desempenho, característica de carcaça e bactérias total do intestino de frango de corte. Ciência Agrotécnica, Lavras, v. 29, n. 1, p. 223-231, 2005.

SANTOS, W. G. Manose na alimentação de leitões na fase de creche: desempenho, parâmetros fisiológicos e microbiológicos. 2002. Dissertação (Mestrado em Zootecnia) - Universidade Federal de Lavras, Lavras.

SILVA, C. A.; ZOTTI, E. Antimicrobianos na suinocultura: aspectos técnicos e práticos de uso. In: ALFIERI, A. F.; BARRY, A. F.; ALFIERI, A. A.; SILVA, C. A.; DALLANORA, D.; ZOTTI, E.; ALBERTON, G. C.; RODRIGUES, I. M. T. C.; MACHADO, I. P.; GRIESSLER, K.; MORES, M. A. Z.; DILTRICH, R. I.; STARKL, V. Tópicos em sanidade e manejo de suínos. Campinas: Curuca, 2010. p. 137-164.
SOUZA, C. F.; LUCAS JÚNIOR, J.; FERREIRA, W. P. M. Biodigestão anaeróbia de dejetos de suínos sob efeito de três temperaturas e dois níveis de agitação do substrato - considerações sobre a partida. Engenharia Agrícola, Jaboticabal, v. 25, n. 2, p. 530-539, 2005.

SPINOSA, H. S. Antibióticos: aminoglicosídeos, polimixinas, bacitracina e vancomicina. In: SPINOSA, H. S.; GÓRNIAK, S. L.; BERNARDI, M. M. Farmacologia aplicada à medicina veterinária. 4. ed. Rio de Janeiro: Guanabara Koogan, 2006. p. 472-476.

TUCCI, F. M. Efeitos da adição de agentes tróficos na dieta de leitões desmamados sobre a renovação celular da mucosa intestinal, enzimas digestivas e desempenho. 2003. Tese (Doutorado em Zootecnia) - Universidade Estadual Paulista, Jaboticabal.

WATKINSON, A. J.; MURBY, E. J.; COSTANZO, S. D. Removal of antibiotics in conventional and advanced wastewater treatment: implications for environmental discharge and wastewater recyling. Water Research, Netherlands, v. 41, n. 20, p. 4164- 4176, 2007. 
